\title{
A PRELIMINARY INVESTIGATION OF FUTURE CLIMATE SCENARIOS FOR IRELAND
}

\author{
John Sweeney and Rowan Fealy
}

John Sweeney, National Institute for Regional and Spatial Analysis, Department of Geography, National University of Ireland, Maynooth, Republic of Ireland (corresponding author; e-rnail: lohn.Sweeney@May.ie); Rowan Fealy, Department of Geography, National University of Ireland, Maynooth, Republic of Ireland.

\begin{abstract}
Ongoing improvements in computing and in climate modelling now permit much more detailed climatic scenarios to be produced as an aid to potential impact assessment. We have employed a downscaling approach, using the UKCIP (UK Climate Impacts Programme) gridded climatology for Ireland at a $10 \mathrm{~km}$ resolution to produce preliminary scenarios for temperature and precipitation for the year 2050. Warming of approximately $0.2^{\circ} \mathrm{C}$ per decade is indicated. Precipitation changes cannot yet be confidently predicted, though increases are likely during the winter months. Contradictory signals for changes in summer rainfall are evident from model output and circulation typing-based approaches. Increased soil moisture deficits are likely during summer, and increased wetness, is likely during winter, particularly in western Ireland. We make some preliminary comments on the implications of these changes for the natural environment and agricultural practices.
\end{abstract}

\section{INTRODUCTION}

Current global losses of biodiversity are alarming, with estimates of the rate of extinction of species running at around 27,000 per year (Wilson 1992; see also Gillen and O'Donovan, this volume). High rates of loss of genetic diversity and ecosystem diversity are also occurring (Graves and Reavey 1996). Whereas past losses have been largely attributed to the spread and increased environmental impact of people, it seems likely that future losses will increasingly result from human-induced global climate change. When climate changes, habitats may disappear: new ecological niches are created, whereas others are destroyed. Climate change considerations must therefore be seen as central to the protection of biodiversity and indeed to future ecological management practices. In planning for the effects of future global climate change on biodiversity, it is obviously essential to have information on the likely magnitude and rates of change. This paper attempts to provide preliminary estimates of these parameters for Ireland.

For much of the twentieth century, climate was regarded as a largely fixed entity. The climatic fingerprint of a place was frequently assumed to be adequately characterised by three decades or so of observations, from which estimations of extreme high-magnitude-low-frequency events were extrapolated. There is now a realisation that this confidence in climate stability was seriously misplaced. Concurrent with this shift in academic thinking, public awareness of ongoing climate change has heightened, and the perception that key changes in the frequencies of extreme events are occurring (which may or may not be justified) now permeates society. Public concerns have been reflected in political concerns, as witnessed by the establishment of the Intergovernmental Panel for Climate Change (IPCC) in 1988. Since that date, three influential IPCC reports have pointed to the likelihood that future climate change will be more rapid and potentially more hazardous than anything that has occurred over the past millennium. The second of these reports (IPCC 1995) advanced more modest projections of future changes, partly in recognition of the countervailing effect that growing atmospheric aerosol loading might have on rates of global warming. The breathing space that these projections might predict has now been reduced in the recently published Third Assessment Report (IPCC 2001), and it is increasingly recognised that the era of reducing estimates may be ending. With this has come the realisation that the Kyoto Protocol may be too little, too late: the protocol may be incapable of producing the radical changes in emissions necessary to ward off more serious climatic dislocation later this century.

GENERAL CIRCULATION MODELS AND THE GROWTH OF COMPUTING POWER

Early general circulation models (GCMs) were severely constrained by computing limitations. Typical horizontal grid sizes of $300-1000 \mathrm{~km}$ and 
two to nineteen vertical levels could be improved only by sacrificing other inputs or reducing the number of time integration steps. As a result, the needs of researchers could not be adequately addressed (Cohen 1990). These concerns are now being rapidly overcome. Whereas the largest computers available in the 1970 s could typically handle ten million floating point operations per second, today's largest models are on the verge of being a million times faster (Fig. 1). As a result, grid size can be reduced: currently, the grid size for the largest models is about $250 \mathrm{~km}$ in the horizontal and about $1 \mathrm{~km}$ in the vertical. Time steps can also be reduced. These are now down to a half-hour, enabling transient models, which take account of gradual changes in forcing factors such as greenhouse gas concentrations, to become much more realistic. Greatly increased computer power has also enabled other models, particularly oceanic circulation models, to be run in tandem with GCMs and generally has facilitated much better parameterisation of sub-grid-scale phenomena such as radiation, clouds and land-surface processes. Increased computer power has also facilitated the use of ensemble runs, whereby several model runs with slightly different input parameters may be compared to examine the sensitivity and uncertainty characteristics of model predictions.

Perhaps the most important result of the recent dramatic improvements in computing power has been the ability to run regional climate models at even finer grid scales, typically of the order of tens of kilometres. In a regional climate model ( $R C M$ ), boundary conditions for the region of interest are usually supplied by a full-scale coupled ocean-atmosphere GCM, which drives a nested regional-scale model able to incorporate a much higher resolution of inputs and outputs than would otherwise be possible (Giorgi and Francisco 2000). A good example of this is the exploration of regional climate change scenarios for Scotland that was recently carried out using the Hadley Centre regional climate model (HadRM2) at a resolution of $50 \mathrm{~km}$ (Hulme et al. 2001). However, some difficulties with this approach persist, and it is not yet clear whether regional climate models offer a technique superior to statistical downscaling from the parent GCM. However, it is these regional scales that are ultimately important to national policy makers, and they alone offer the possibility of tailoring climatic scenarios more specifically to projected effects and possible mitigation efforts (Lamb 1987).

\section{CLIMATE SCENARIOS: THE PROBLEM OF EMISSION ASSUMPTIONS}

The production of climate change scenarios for

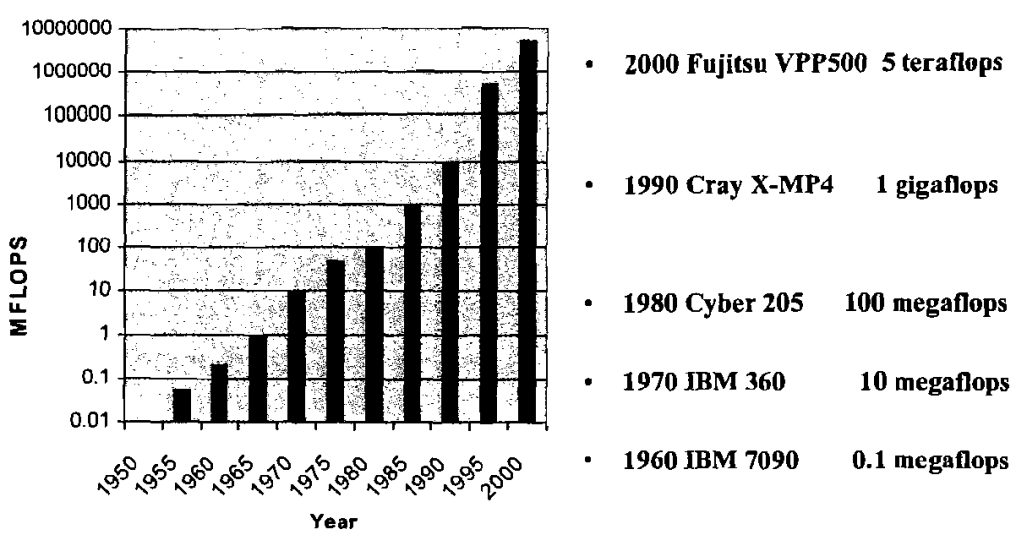

Fig. 1-Growth of computing power, in millions of floating point operations per second.

any part of the world is fraught with uncertainties, most obviously with regard to future emissions of greenhouse gases. Key input variables such as population change, economic growth, technological progress, energy consumption and the development of greenhouse gas abatement policies can only be estimated, often very tentatively. The first generation of emission scenarios, which was published by the IPCC in 1990 (IPCC 1990), contained four different sets of assumptions concerning these variables, ranging from a 'business as usual' energy supply assumption to one increasingly dominated by renewables and nuclear energy. These four scenarios evolved by 1992 into six categories (Leggett et al. 1992), which were used as the basis for the Second Assessment Report (IPCC 1995). Since then, it has become apparent that some of the assumptions, particularly those relating to sulphur dioxide $\left(\mathrm{SO}_{2}\right)$ emissions, are unlikely to be realised, and a new series of scenarios has been published in the IPCC Special Report on Emissions Scenarios (SRES) (IPCC 2000). The SRES offers 40 different emission scenarios that cover a wider range of emissions than their predecessors and are couched in terms of 'storylines' with strong socio-economic undertones. For example, SRES A1 is based on assumptions that the pursuit of personal wealth will be considered more important than environmental quality and that rapid economic growth will be accompanied by lower population growth and new and more efficient technologies. SRES B1, in contrast, emphasises a lesser commitment to materialism and concerted global efforts towards environmental sustainability and social equity. Such language is at first sight unusual in the scientific literature but indicates the growing convergence of socio-economic and scientific models seeking to grapple with the problem of global change.

The generally lower estimates for $\mathrm{SO}_{2}$ emissions suggested by the SRES have resulted in 
predictions of increased temperature change in the Third Assessment Report (IPCC 2001). The SRES scenarios produce estimated increases in global temperature in the range $1.5-6^{\circ} \mathrm{C}$ for the period 1990-2100, but the most likely outcome is a rise in global temperature of approximately $3^{\circ} \mathrm{C}$ over this period. The equilibrium response of the global mean surface air temperature to a doubling of atmospheric carbon dioxide $\left(\mathrm{CO}_{2}\right)$ averaged over a range of current models is estimated at $2.8^{\circ} \mathrm{C}$ (IPCC 2001). Of course, the natural trend on which this will be superimposed is unknown and may either exacerbate or diminish the temperature change realised.

\section{GLOBAL SCENARIOS}

Since the computing capacity and technical expertise required to support sophisticated general circulation models is today so demanding, their development and operation is confined to a relatively small number of key centres. Instead, considerable use is made of climate scenario generators, which can emulate the behaviour of more sophisticated models and provide quick projections for individual regions. The best-known of these is the MAGICC/SCENGEN package (Hulme et al. 2000), which allows users to examine the likely climatic consequences of a large range of future emission scenarios. MAGICC is a single software package incorporating a suite of coupled gas-cycle, ice-melt and climate models. In this way it enables the operation of GCMs by emulating user-defined emission scenarios. Users may also change model parameters such as aerosol forcing, net land-use change, $\mathrm{CO}_{2}$ emissions and climate sensitivity (i.e. equilibrium temperature response to $\mathrm{CO}_{2}$ doubling). SCENGEN then uses the output of MAGICC to produce comparisons with observed regional climate data sets. Scenarios for temperature, precipitation and cloud cover are generated with a spatial resolution of $5^{\circ}$ latitude/longitude. A rather simplistic method is used for this downscaling, on the assumption that the spatial pattern of future climate will approximate to the present-day pattern, despite changes in the individual parameters of climate. This is known as 'pattern scaling' (Santer et al. 1990).

For construction of scenarios, it has been suggested that a better estimate of the global-warming signal would be obtained by averaging the output of several GCMs than by using a single model (Santer et al. 1990). Accordingly, MAGICC/SCENGEN was used to produce a global scenario for 2050 based on the average of three GCMs: NCAR-DOE (USA), ECHAM4 (Germany) and HadCM2 (UK).
Emission scenario SRES B2 was selected, and consideration of sulphate aerosol effects was incorporated into the model run. The selected scenario projects $\mathrm{CO}_{2}$ emissions of $13.7 \mathrm{GtC}$ by 2100 and $\mathrm{SO}_{2}$ emissions of $51 \mathrm{TgS}$. Whereas the $\mathrm{CO}_{2}$ estimate is similar to values used in earlier IPCC projections, the $\mathrm{SO}_{2}$ estimate is considerably reduced. Results are shown in Fig. 2.

Globally, the northern high latitudes are seen to experience the greatest warming. This is primarily a result of the ice-albedo feedback effect, whereby the change from a bright, reflective ice surface to a dark, absorbing land surface accentuates the warming. Continental interiors also warm by approximately $2^{\circ} \mathrm{C}$ over the next half-century. Low-latitude zones and oceanic margins appear to warm only by average or less-than-average amounts. This, in part, probably reflects the negative feedback in these zones of additional cloud cover in a warmer world. As a mid-latitude country, Ireland appears to warm by a value close to the global average of just over $1^{\circ} \mathrm{C}$ by 2050 .

\section{IRISH CLIMATE SCENARIOS}

The coarse resolution of GCM output has prompted a number of approaches whereby finer regional details may be ascertained. Regional climate modelling has already been discussed. A second approach involves using atmospheric GCM directly to produce high-resolution output for a restricted time period (Cusbach et al. 1995). However, this has not yet been widely employed. The most common approach has been the third method, which entails statistical downscaling of GCM output. This is achieved using established relationships at a large scale, such as $500 \mathrm{hPa}$ heights and surface meteorological variables, which would be expected to remain robust in a changing climate situation (Wilby and Wigley 1997).

The simplest form of statistical downscaling involves applying GCM output directly to a high resolution baseline climatology. This has many drawbacks, not least because the existing spatial pattern is largely replicated for the future scenario. However, it does provide a useful preliminary product that can subsequently be improved as the baseline climatology is improved and as the statistical relationships between larger-scale meteorological controls and baseline climatology become more sophisticated. This approach has been employed in the preliminary production of climate scenarios for Ireland for 2050 through the use of the gridded baseline climatology for Ireland derived as part of the Climate Impacts LINK project of the University of East Anglia (Hulme and Jenkins 1998). 


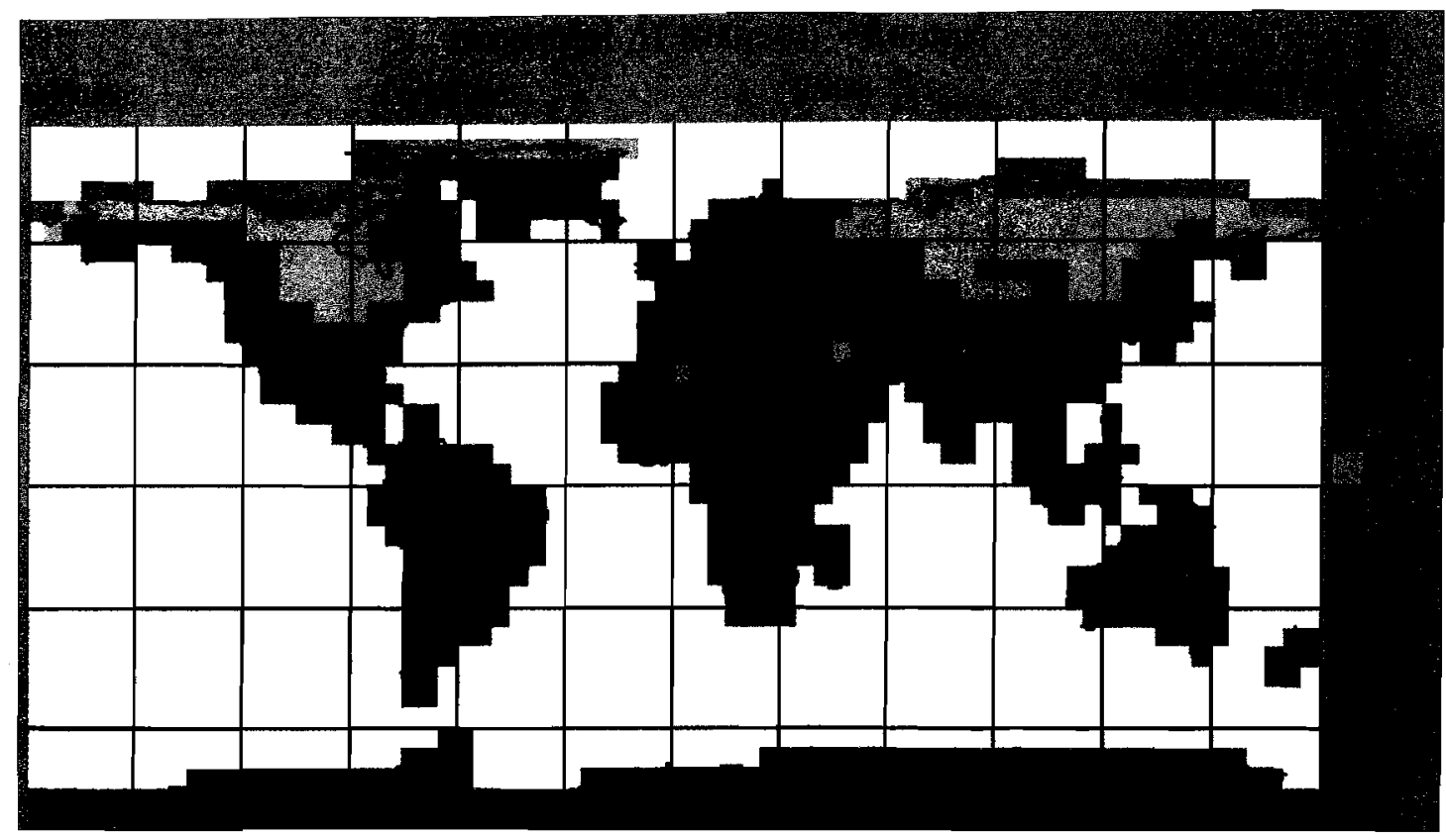

Fig. 2-Projected global temperature changes 1990-2050 using MAGICC and SCENGEN. This projection is based on an average of the standardised and rescaled patterns from three leading GCMs and employs the Special Report on Emission Scenarios B2 assumptions for greenhouse gas emissions over the period. The effects of aerosol-induced changes are also incorporated by use of the 'sulphate option'.

Fig. 3 shows mean winter temperatures (December, January, February) in the range $6-8^{\circ} \mathrm{C}$ by mid-century over much of the southern half of Ireland and in almost all coastal areas. In the extreme south-west, values in excess of $8^{\circ} \mathrm{C}$ will be experienced. Winters in Northern Ireland and in the north midlands will be similar to those of Cork/Kerry during the 1961-90 period. Most important from a biodiversity perspective, however, will be the implications of these changes for the growing season. A reduction in frost frequency, the possibility of plant growth taking place almost all year round and the increased concentration of $\mathrm{CO}_{2}$ in the atmosphere can be expected to increase standing biomass, increase the ratio of roots to shoots and affect animal reproductive biology (Jeffrey et al. 1991). Fig. 3 also shows mean summer temperatures (June, July, August) of over $16^{\circ} \mathrm{C}$ as far north as coastal County Down by mid-century. This may take some species outside their optimum temperature environment and alter competitive balances. However, if combined with reduced summer precipitation amounts, higher summer temperatures are likely to result principally in increased evapotranspiration losses and, consequently, increased drought stress. Some amelioration of this increased evapotranspiration may, however, occur as a result of partial stomatal closure, which a $\mathrm{CO}_{2}$-enriched atmosphere will encourage.
Fig. 4 suggests that precipitation increases will occur in both winter and (to a much lesser extent) summer in a greenhouse-warmed Irish climate. The strongest signal is seen in winter in western Ireland, where significant increases are projected. No discernible signal is apparent for summer and in fact most models project drier summers for Ireland than at present. However, it must be stressed that model output is much less reliable with respect to precipitation as opposed to temperature. This is because clouds both absorb and reflect solar and terrestrial radiation, and thus exhibit both positive and negative feedback effects. The net result of this is not well understood. Accordingly, models show a greater spread of variance in predicting precipitation changes than temperature changes, and output of scenario production cannot yet be relied upon.

An alternative approach, based on typing of circulation/precipitation yields, has been employed by Sweeney $(1994,1997)$ to estimate changes in precipitation. This uses the Lamb Circulation Catalogue to classify each day's precipitation into a synoptic category. Yields by category are then established over a period of up to a century. Circulation frequencies corresponding to greenhouse-warmed climate in winter and summer may then be used to generate hypothetical rainfall receipts. Caution must be exercised with this technique, however, as it implicitly assumes that precipitation yields from particular airmass trajectories will not alter significantly as climate 


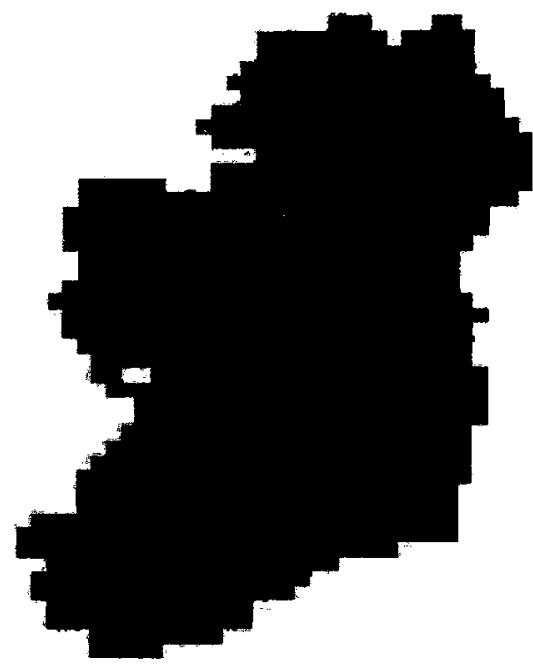

1961-90 Mean Daily Winter Temperature

\begin{tabular}{|c|c|}
\hline Temperature \\
Deg C \\
\hline & $>18$ \\
& 14.18 \\
& 12.14 \\
10.12 \\
8.10 \\
0.8 \\
4.8 \\
2.4 \\
\hline$<2$ \\
\hline
\end{tabular}

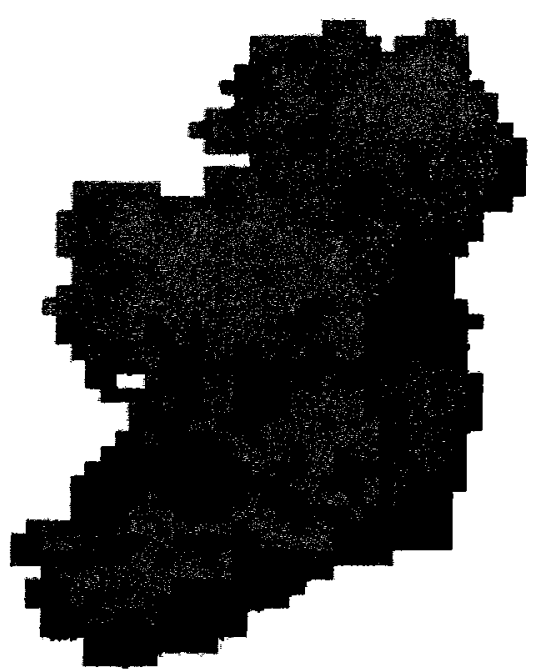

1961-90 M san Dally Summer Temperature

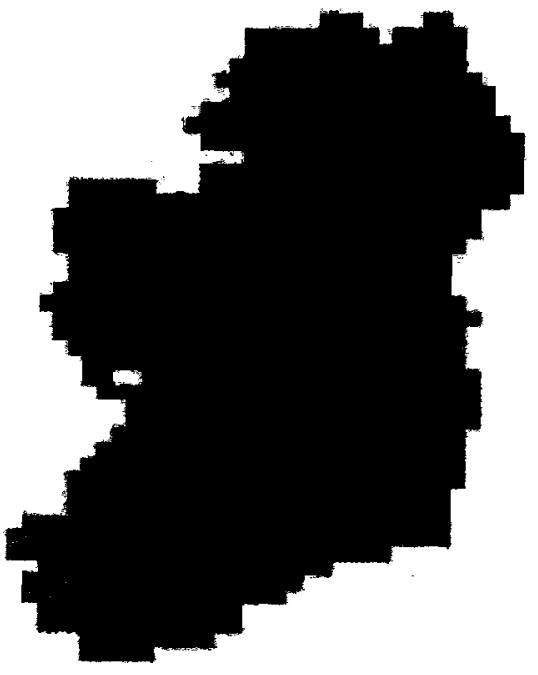

2050 Mean Daily Winter Temperature

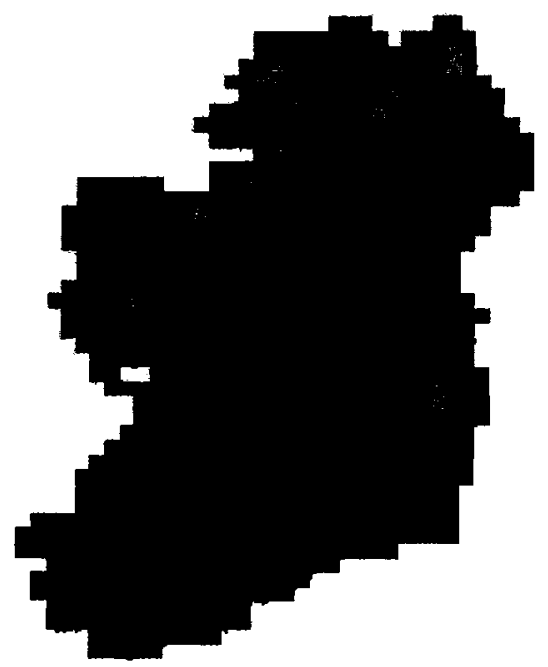

2050 Mean Daly Summer Temperature

Fig. 3-Projected winter and summer temperature changes for Ireland from the UKCIP98 climatic scenario downscaled from the HadCM2 global climate model.

changes. This assumption may not be entirely valid because sea surface temperatures can also be expected to change, if somewhat conservatively, as global warming occurs. Subject to this caveat, Fig. 5 suggests that whereas significant increases will occur in western parts in winter, equally significant reductions in summer rainfall are likely to occur in eastern and central Ireland. Such changes, if realised, will probably constitute the most significant effect on biodiversity due to Ireland's 


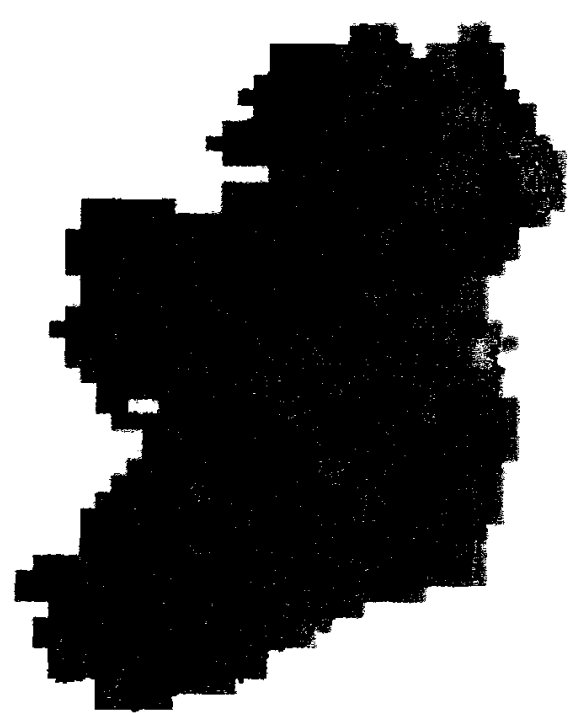

1961-90 Mean Daily Winter Precipitation

\begin{tabular}{|c|c|}
\hline \multirow{2}{*}{\multicolumn{2}{|c|}{$\begin{array}{l}\text { Precipitation } \\
\text { mm/day }\end{array}$}} \\
\hline & \\
\hline & 0.1 .0 \\
\hline & $10 \cdot 2.0$ \\
\hline & $20 \cdot 3.0$ \\
\hline & $30-4.0$ \\
\hline & $40 \cdot 8.0$ \\
\hline & $5.0 \cdot 6.0$ \\
\hline & $0.0 \cdot 7.0$ \\
\hline & $7.0 \cdot 8.0$ \\
\hline & $8.0 \cdot 8.0$ \\
\hline
\end{tabular}

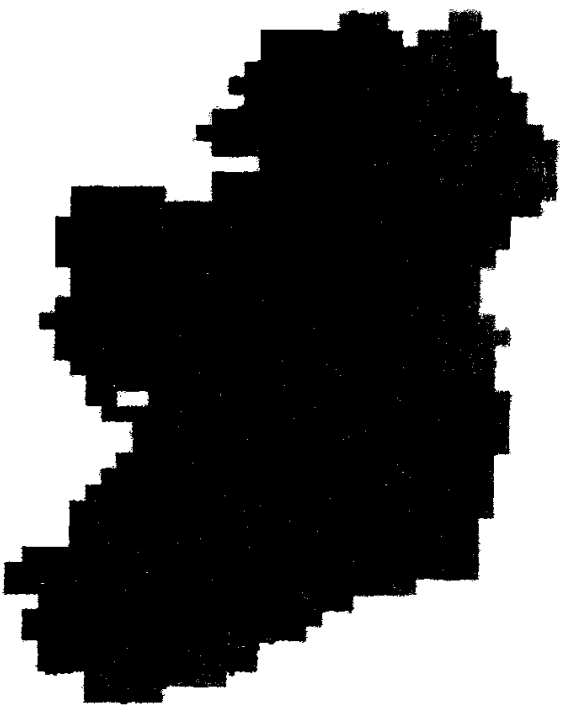

2050 Mean Daily Winter Precipitation

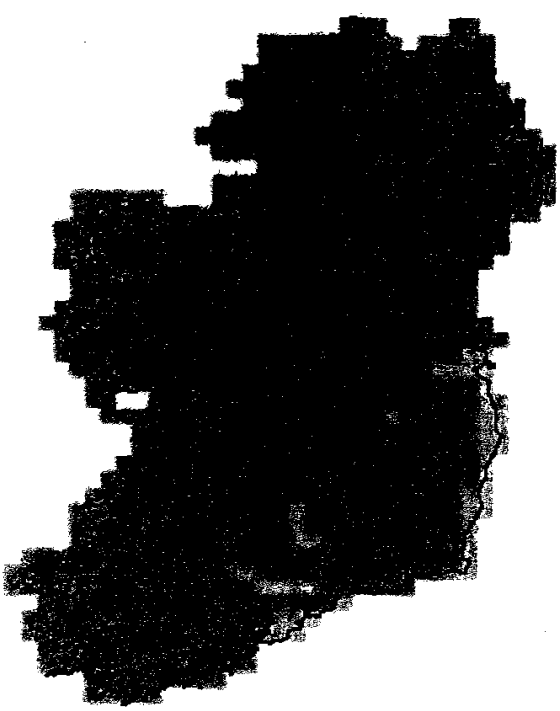

2050 Mean Daily Summer Precipitation

1961-90 Mean Daily Summer Precipitation

Fig. 4-Projected winter and summer precipitation changes for Ireland from the UKCIP98 climatic scenario downscaled from the HadCM2 global climate model.

changing climate. It is likely that precipitation changes will also have major consequences for agticulture and water-resource management.
Reductions in summer soil moisture and increases in winter wetness can be expected to affect many habitats, particularly peatlands and other wetland 

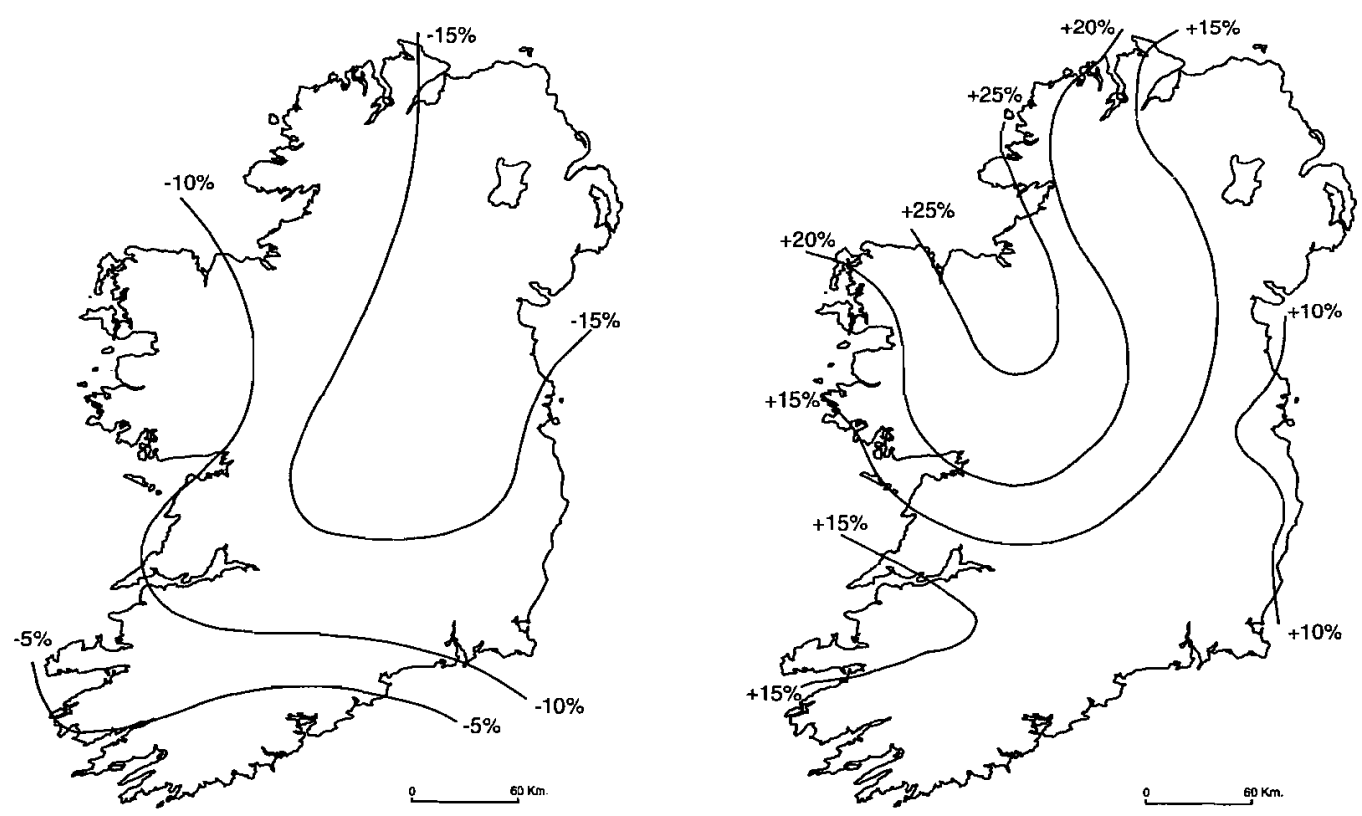

Fig. 5-Projected summer (left) and winter (right) precipitation changes from the circulation/analogue method (after Sweeney 1997).

ecosystems. More detailed scenarios will be required to examine the likely effects of climate changes on such vulnerable habitats further.

\section{CONCLUSIONS}

Preliminary investigations of future climate scenarios for Ireland suggest that warming of approximately $0.2^{\circ} \mathrm{C}$ per decade, superimposed on an unknown 'natural' trend, can be expected. International policy measures currently envisaged can be expected to reduce this figure only by the end of the twenty-first century. As at present, nearby oceanic temperatures will control Irish temperatures, particularly in winter, and as a lag in sea temperature warming is likely to occur, slower warming is probable in Ireland than further east in Europe.

Though less confidence can be placed in model output for precipitation changes, both model and analogue approaches suggest increases in winter precipitation of up to $15 \%$ in western parts. However, greater uncertainty exists regarding summer precipitation changes, and further studies are needed to resolve this issue. If realised, increased surface water flows in winter would have important implications for flood incidence, particularly in western Ireland. Summer drying would have equally important consequences in terms of soil moisture conditions, reduced dilution water for pollution management and domestic/industrial consumption.

The changes envisaged for Irish climate are likely to have considerable implications for biodiversity in some habitats, such as coastal wetlands, peatlands and some upland areas. To address these issues fully, more detailed climate scenarios, more advanced statistical downscaling of GCM output and studies of the effects of these predicted changes on vulnerable ecosystems are required. These measures are presently being undertaken.

\section{ACKNOWLEDGEMENTS}

The authors acknowledge the assistance rendered by the use of the MAGICC/SCENGEN climatic scenario generator produced by the Climate Research Unit of the University of East Anglia with the support of the UNDP-GEF National Communications Support Programme. The UKCIP98 Climatic Scenario CD-ROM has been supplied by the Climate Impacts LINK Project (DETR Contract EPG 1/1/68) on behalf of the UKCIP and the Meteorological Office (Hadley Centre).

\section{REFERENCES}

Cohen, S.J. 1990 Bringing the global warming issue closer to home: the challenge of regional impact studies. Bulletin of the American Meteorological Society 71, 520-6.

Cusbach, U., Waszkewitz, G., Hegerl, H. and Perlwitz, J. 1995 Regional climate changes as simulated in time-slice experiments. Climate Change 31, 273-304. 
Giorgi, F. and Francisco, R. 2000 Uncertainties in regional climate change prediction: a regional analysis of ensemble simulations with HadCM2 coupled AOGCM. Climate Dynamics 16, 169-82.

Graves, J. and Reavey, D. 1996 Global environmental change. Harlow, England. Longman.

Hulme, M. and Jenkins, G.J. 1998 Climate change scenarios for the United Kingdom. UKCIP Technical Report no. 1. Norwich, England. Climatic Research Unit.

Hulme, M., Wigley, T., Barrow, E., Raper, S., Centella, A., Smith, S. and Chipanshi, A.C. 2000 Using a climatic scenario generator for vulnerability and adaption assessments: MAGICC and SCENGEN version 2.4 workbook. Norwich, England. Climatic Research Unit.

Hulme, M., Crossley, J. and Lu, X. $2001 A_{n}$ exploration of regional climate change scenarios for Scotland. Edinburgh. Scottish Executive Central Research Unit.

IPCC [Intergovernmental Panel on Climate Change] 1990 Climate change: the IPCC scientific assessment. J.T. Houghton, G.J. Jenkins and J.J. Ephraums (eds), Contribution of Working Group I to the First Assessment Report of the Intergovernmental Panel on Climate Change. Cambridge, England. Cambridge University Press.

IPCC [Intergovernmental Panel on Climate Change] 1995 Climate change 1995: the science of climate change. J.T. Houghton, L.G. Meira Filho, B.A. Callander, N. Harris, A. Kattenberg and K. Maskell (eds), Contribution of Working Group 1 to the Second Assessment Report of the Intergovemmental Panel on Climate Change. Cambridge, England. Cambridge University Press.

IPCC [Intergovernmental Panel on Climate Change] 2000 Special report on emissions scenarios. $\mathrm{N}$. Nakicenovic and R.J. Swart (eds), Working Group III, Intergovermmental Panel on Climate Change. Cambridge, England. Cambridge University Press.

IPCC [Intergovernmental Panel on Climate Change] 2001 Climate change 2001: the scientific basis.
J.T. Houghton, Y. Ding, D.J. Griggs, M. Noguer, P.J. van der Linden and D. Xiaosu (eds), Contribution of Working Group $I$ to the Third Assessment Report of the Intergovemmental Panel on Climate Change. Cambridge, England. Cambridge University Press.

Jeffrey, D.W., Grainger, J.N.R., Dowding, P., Jones, M.B. and Khan, J. 1991 The Irish green mantle and its native fauna. In B.E. McWilliams (ed.), Climate change: studies on the implications for Ireland, 63--87. Dublin. Department of the Environment.

Lamb, P. 1987 On the development of regional climatic scenarios for policy-oriented climatic impact assessment. Bulletin of the American Meteorological Society 68, 1116-23.

Leggett, J., Pepper, W.J. and Swart, R.J. 1992 Emissions scenario for the IPCC: an update. In J.T. Houghton, B.A. Callander and S.K. Varney (eds), Climate change 1992: the supplementary report to the $I P C C$ scientific assessment, 79--95. Working Group I, Intergovernmental Panel on Climate Change. Cambridge, England. Cambridge University Press.

Santer, B., Wigley, T., Schlesinger, M. and Mitchell, J. 1990 Developing climate scenarios from equilibrium GCM results. Report no. 47. Hamburg. Max-Planck-Institut für Meteorologie.

Sweeney, J. 1994 Climate scenarios for Ireland. In J. Feehan (ed.), Climate variation and climate change in Ireland, 110-27. Dublin. The Environmental Institute, University College Dublin.

Sweeney, J. 1997 Global warming scenarios and their implications for environmental management in Ireland. In J. Sweeney (ed.), Global change and the Irish environment, 155-70. Dublin. Royal Irish Academy.

Wilby, R. and Wigley, T.M.L. 1997 Downscaling general circulation model output: a review of methods and limitations. Progress in Physical Geography 21, 530-48.

Wilson, E.O. 1992 The diversity of life. Cambridge, MA. Harvard University Press. 